\title{
Electronic Health Records and Preparedness: Lessons from Hurricanes Katrina and Harvey
}

\author{
Shayne Sebold Taylor $^{1} \cdot$ Jesse M. Ehrenfeld ${ }^{1}$
}

Published online: 19 September 2017

(C) Springer Science+Business Media, LLC 2017

The levees of New Orleans broke on August 29, 2005. The bayous of Houston crested on August 29, 2017. The resulting floods were catastrophic and deadly for each community. It's been a busy twelve years in America: three presidents have resided in the White House, Osama bin Laden was killed, gay marriage supported in the Supreme Court, and we've cured Hepatitis C, to name a few. While the lesson about climate change continues to fall on ears deafened by the whirs of the oil rigs, there was one significant mass casualty that was spared 2017 when compared to 2005: medical records. As far as casualties go, this one certainly lacks a certain heroism. Let us not forget however, that one million people were displaced in the aftermath of Hurricane Katrina, each of those a patient with a history. A patient, for example, on a fluctuating diuretic regimen dictated by a tenuous volume status, or one with drug resistant HIV now setting up shop in a new community, or a cancer patient who just completed cycle 2 of 5 of chemotherapy, arriving in your practice asking for help.

In the twelve years that separated Hurricane Katrina from Hurricane Harvey, the advances to the electronic health record
(EHR) has been powerful, allowing for safe continuity of care in the face of catastrophe. A Houston clinic may now be underwater, but with patient interactive portals that allow patients to access their labs and medications remotely, a patient of that clinic has a better chance of seeing a new physician in a neighboring town and providing an accurate picture of his or her medical history.

As hospitals were forced to evacuate and transfer their patients to various facilities, systems like the Greater Houston Healthconnect, a health information exchange (HIE) program adopted in 2010, allowed providers of different medical systems to efficiently exchange patient information. While the storms raged outside and trucks floated like ants down the interstate, physicians were able to provide high quality emergency care in a variety of settings ranging from a tertiary academic hospital to a make-shift convention center booth with the help of a laptop. These twelve years bookended by August 29th, have been productive; the electronic health record serving as one of the unsung heroes that deserves the credit where credit is due.

This article is part of the Topical Collection on Systems-Level Quality Improvement.

Jesse M. Ehrenfeld

jesse.ehrenfeld@Vanderbilt.Edu

1 Vanderbilt University Medical Center, Nashville, TN, USA 